\title{
Mid Trimester Transvaginal Ultrasound Assessment of Cervix for Prediction of Primary Caesarean Section*
}

\author{
Mamta Rath Datta\#, Shikha Parashar, Priyanka Mukherjee, Sarita Kumari, \\ Ankush Nandkishor Raut \\ Department of Obstetrics and Gynecology, Tata Main Hospital, Jamshedpur, India \\ Email: "drmamtadatta@hotmail.com,"drmamtadatta@gmail.com
}

Received 21 November 2015; accepted 13 December 2015; published 16 December 2015

Copyright (C) 2015 by authors and Scientific Research Publishing Inc.

This work is licensed under the Creative Commons Attribution International License (CC BY). http://creativecommons.org/licenses/by/4.0/

(c) (i) Open Access

\section{Abstract}

Objectives: To assess the role of mid-trimester transvaginal sonographic assessment of cervix in predicting the risk of primary cesarean section. Methods: Hundred pregnant women, who attended out-patient department of Tata Main Hospital for ante natal examination, from $1^{\text {st }}$ December 2011 to $1^{\text {st }}$ December 2012, were taken up for the study. Only those who had confirmed dates were included in the study. Transvaginal sonography was done at 18 - 26 week to measure cervical length. Parameters studied were gestational age at delivery, whether spontaneous or induced, duration of labor, pregnancy outcome and mode of delivery and indication for cesarean section. Results: Majority of LSCS were in the group with cervical length $\geq 4 \mathrm{~cm}(57.1 \%)$ with "p" value of $<0.0001$. Only $13.8 \%$ women who had vaginal delivery had cervical length $\geq 4 \mathrm{~cm}$. Out of the 32 women with cervical length $\geq 4 \mathrm{~cm}, 26(81.3 \%)$ required induction of labor and 10 (31.3\%) delivered after 40 weeks. Mean cervical length for spontaneous onset of labor was $3.11 \pm 0.85 \mathrm{~cm}$ and for induction of labor was $4.36 \pm 1.11 \mathrm{~cm}$ ("p" value $\leq \mathbf{0 . 0 0 1}$ ). Multiple logistic regression analysis was performed to study outcome variable of mode of delivery. Cervical length and induction to delivery interval were found to be independent predictor of mode of delivery. In the receiver operating characteristic (ROC) curve analysis, the best cut-off point for prediction of primary cesarean section was $40 \mathrm{~mm}$ for cervical length. Sensitivity, specificity, positive predictive value and negative predictive value of cervical length as a predictor of mode of delivery was 54.8\%, 91.4\%, 82.1\% and $73.6 \%$ respectively. $R^{2}$ (coefficient of determination) was 0.271 . Conclusion: Transvaginal cervical length measurement at mid trimester can be used as a predictive tool to determine the risk of primary cesarean section as well as the need of induction of labor.

\footnotetext{
${ }^{*}$ Capsule: This study assesses the efficacy of transvaginal ultrasound measurement of cervical length as predictor of primary caesarean section.

"Corresponding author.
}

How to cite this paper: Datta, M.R., Parashar, S., Mukherjee, P., Kumari, S. and Raut, A.N. (2015) Mid Trimester Transvaginal Ultrasound Assessment of Cervix for Prediction of Primary Caesarean Section. Open Journal of Obstetrics and Gynecology, 5, 855-863. http://dx.doi.org/10.4236/ojog.2015.515121 


\section{Keywords}

\section{Ultrasound, Prediction, Miscarriage}

\section{Introduction}

The cervical length is known to influence outcome of labor. The major cause of primary cesarean section is poor progression of labor (dystocia). In recent years, a few workers have shown that cervical length at mid-pregnancy is an independent predictor of risk of cesarean section in primiparous women. Increased cervical length has also been found to be associated with risk of increased induction to delivery interval and poor progress of labor [1]-[4].

Various methods of cervical length measurement have been used which includes digital, transabdominal, transvaginal and transperineal. Transvaginal sonographic method of cervical length measurement is generally the most preferred method. However, the results of studies that have evaluated the accuracy of transvaginal ultrasound for the prediction of the outcome of induction remain controversial. Some investigators have reported that transvaginal ultrasonographic assessments of the cervix are of value for predicting the outcome of induction [5] [6], whereas others have argued against it [7] [8].

\section{Aims and Objectives}

To assess the role of mid-trimester transvaginal sonographic assessment of cervix in predicting the risk of primary cesarean section.

\section{Material and Methods}

This prospective study was approved by the institutional review board and ethical committee of Tata Main Hospital, Jamshedpur.

STUDY DESIGN: Hospital based prospective nonrandomized single blind study.

SAMPLE SIZE: Hundred pregnant primigravid women, who attended out-patient department of Tata Main Hospital for ante natal examination, from $1^{\text {st }}$ December 2011 to $1^{\text {st }}$ December 2012, were taken up for the study.

INCLUSION CRITERIA: Primigravidas with certain dates, live singleton pregnancies with vertex presentation were included in the study.

EXCLUSION CRITERIA: Those with uncertain dates, multiple pregnancies, previous uterine or cervical surgeries, history of allergy to prostaglandins or asthmatics or medical disorders, fetal anomalies, abnormal non stress tests, presence of contraindications for vaginal birth were excluded from the study.

\subsection{Method of Data Collection}

Informed consent was taken prior to enrollment of the women in the study.

On attending antenatal outpatient department, a detailed history was taken. Gestational age was confirmed by last menstrual period and early first trimester ultrasound scan. Transvaginal sonography was done at 18 - 26 week was done to measure cervical length. The cervical length was taken from the point of internal os to the external os. Cervical lengths were determined by ultrasonograophers trained in these methods and quality control was performed on a regular basis by the consultant ultrasonologists.

On admission to labour ward, a detailed history was taken and a thorough clinical examination was done by the resident in labour ward, who was unaware of the sonographic findings. Antenatal risk factors and the indication for induction of labour were noted. The patient was followed till delivery. The following parameters were noted: gestational age at delivery, whether spontaneous or induced, method of induction, duration of labour, pregnancy outcome and mode of delivery and indication for cesarean section.

\section{Method of Measurement of Cervical Length by Transvaginal Ultrasound}

At midtrimester, transvaginal ultrasonographic assessment of cervical length and presence of funneling and the depth of funneling was performed using Aloka IPF-1506 ultrasound machine equipped with a $5 \mathrm{MHz}$ transvaginal probe. The women were asked to empty their bladder and were placed in dorsal lithotomic position. The probe was covered with a latex condom and gel placed between the transducer and the cover and also on the surface. 
The probe was gently placed at the anterior fornix of the vagina to obtain a saggital view of the complete cervix including the internal os, external os and the endocervical canal. The probe was slowly withdrawn until the image blurred and the insertion pressure was increased only enough to restore a clear cervical image. The cervical image was magnified to at least $75 \%$ of the screen and the electronic markers were placed at the farthest points between internal os and external os and the cervical length was measured as a straight line. Measurement of cervical length was made when all of the following criteria were fulfilled:

1) The internal os was either flat or in the form of an isosceles triangle.

2) The whole length of the cervical canal could be visualized.

3) A symmetrical image of the external os was obtained.

4) The distance from the surface of the posterior lip to the cervical canal was equal to the distance from the anterior lip to the cervical canal.

Each examination is performed for 3 to 5 minutes to observe whether any dynamic cervical changes occur. The cervical length was measured 3 times and the shortest of the three measurements was used.

\subsection{Statistical Analysis}

Data was entered into statistical package for the social science system version SPSS 17.0. Continuous variables are presented as mean $\pm \mathrm{SD}$, and categorical variables are presented as absolute numbers and percentage. The comparison of normally distributed continuous variables between the groups was performed using Student's $t$ test. Nominal categorical data between the groups were compared using Chi-squared test and standard error of proportions. Correlation was also done between various variables (cervical length, maternal age, gestational age at onset of labor/induction etc). Receivers operating characteristic (ROC) curves were used to assess the ability of cervical length by TVS, to predict risk of cesarean section. The best cut-off values of cervical length to predict successful vaginal delivery and risk of cesarean section were determined. Multiple logistic regression analysis was also used to assess effect of the independent parameters on the mode of delivery.

\subsection{Results and Observation}

In the study population $(\mathrm{n}=100)$, the cervical length was studied in 4 groups-cervical lengths $<2 \mathrm{~cm}, 2-2.9$ $\mathrm{cm}, 3-3.9 \mathrm{~cm}$ and $\geq 4 \mathrm{~cm}$.

Out of total 100 women studied, $58 \%$ had vaginal delivery, out of which $3 \%$ were forceps delivery. Forty two percent (42\%) of the total had cesarean section.

In women with cervical length $<3 \mathrm{~cm}(\mathrm{n}=22)$, majority had spontaneous onset of labor $(\mathrm{n}=20,90.9 \%)$. In women with cervical length of $3-3.9 \mathrm{~cm}, 20$ women (43.5\%) had spontaneous onset of labor and 26 women (56.5\%) had labor induction. In those with cervical length $\geq 4 \mathrm{~cm}$, majority had induced labor ( $\mathrm{n}=26$ of 32 , 81.3\%). The rates of induction of labor were increased significantly with increase in cervical lengths $(\mathrm{p}<0.0001$ when rates were compared between groups with cervix between $2-2.9 \mathrm{~cm}$ and $3-3.9 \mathrm{~cm} ; \mathrm{p}=0.02$ when the groups of $3-3.9 \mathrm{~cm}$ and $>4 \mathrm{~cm}$ were compared) (Table 1 ).

However, in the group whose cervical lengths were between $3-3.9 \mathrm{~cm}$, the difference between induction rates and rates of spontaneous onset of labor was not statistically significant (Relative variate $=1.6$, which is within 2 SD confidence limits using standard error of proportion). There is significantly high chance of having labor induction in those with cervical lengths more than $4 \mathrm{~cm}$ (Relative variate $=6.6$, which is beyond $2 \mathrm{SD}$ confidence limits using standard error of proportion method) (Table 1).

Mean cervical length for spontaneous onset of labor was $3.11 \mathrm{~cm} \pm 0.85$ whereas mean cervical length for induced labor was $4.36 \pm 1.11 \mathrm{~cm}(\mathrm{p}<0.001)$ (Table 1$)$.

Cesarean rates in women with cervix $<2.9 \mathrm{~cm}$ ) was $18.2 \%$ (4 out 22 women). In women with cervical length between $3-3.9 \mathrm{~cm}$, cesarean rate was 30.4\% (14 of 46 women). However, the difference in the cesarean rates in the above two groups was not statistically significant $(p>0.10)$. In women with cervical length more than $4 \mathrm{~cm}$, cesarean rate was $75 \%$ (24 of 32 women). When compared with the group with cervical length between 3 - 3.9 $\mathrm{cm}$, difference was statistically significant. Thus, in this group, cesarean rate was significantly higher than the other 3 groups (Table 2).

On further analysis of the causes for cesarean delivery, it was seen that the group with cervical length $\geq 4 \mathrm{~cm}$ had maximum number of LSCS for failure to progress and failed induction $(\mathrm{p} \leq 0.001)$ (Table 3). Table 4 shows the induction to delivery interval in relation to the cervical length, in our study. There was a significant increase in induction to delivery interval with increase in cervical length. 
Table 1. Cervical length gestation age at onset of labour/induction and mode of onset of labour.

\begin{tabular}{|c|c|c|c|c|c|c|c|}
\hline \multirow{2}{*}{$\begin{array}{c}\text { Mode of onset of } \\
\text { Labor }\end{array}$} & \multirow{2}{*}{$\begin{array}{l}\text { GA at onset of } \\
\text { Labor/Induction }\end{array}$} & \multicolumn{4}{|c|}{ Cervical Length } & \multirow{2}{*}{ Total } & \multirow{2}{*}{$\begin{array}{l}\text { Mean cervical } \\
\text { length }\end{array}$} \\
\hline & & $<2 \mathrm{~cm}$ & $2-2.9 \mathrm{~cm}$ & $3-3.9 \mathrm{~cm}$ & $\geq 4 \mathrm{~cm}$ & & \\
\hline \multirow{4}{*}{ Spontaneous } & $<37$ wks & 3 & 14 & 6 & 0 & 23 & \multirow{4}{*}{$3.11 \pm 0.85 \mathrm{~cm}$} \\
\hline & 37 - 40 wks & 0 & 3 & 14 & 6 & 23 & \\
\hline & $>40$ wks & 0 & 0 & 0 & 0 & 0 & \\
\hline & Total & 3 & 17 & $20^{* *}$ & $6^{* * * *}$ & 46 & \\
\hline \multirow{4}{*}{ Induced } & $<37$ wks & 0 & 0 & 1 & 0 & 1 & \multirow{5}{*}{$4.36 \pm 1.11 \mathrm{~cm}$} \\
\hline & 37 - 40 wks & 0 & 1 & 17 & 16 & 24 & \\
\hline & $>40$ wks & 0 & 1 & 8 & 10 & 19 & \\
\hline & Total & $\mathbf{0}$ & 2 & $26^{* *}$ & $26^{* * * *}$ & 54 & \\
\hline TOTAL & & 3 & $19 *$ & $46^{* / * *}$ & $32^{* *}$ & 100 & \\
\hline
\end{tabular}

p value: ${ }^{*}$ comparing induced labor rates in the groups with cervical lengths $2-2.9 \mathrm{~cm}$ and $3-3.9 \mathrm{~cm}: \mathrm{p}<0.0001$; ${ }^{* *}$ comparing induced and labor rates in the groups with cervical lengths $3-3.9 \mathrm{~cm}$ and $\geq 4 \mathrm{~cm}: \mathrm{p}<0.0001$; ${ }^{* * *}$ comparing induced and spontaneous onset labor rates in the groups with cervical lengths between $3-3.9 \mathrm{~cm}-\mathrm{S} . \mathrm{E}(\mathrm{P})=5.95 \%$ C.I. 42 - 62, Relative variate 1.6 - statistically not significant); ${ }^{* * * *}$ comparing induced and spontaneous onset labor rates in the groups with cervical lengths between $\geq 4 \mathrm{~cm}-\mathrm{S} . \mathrm{E}(\mathrm{P})=5.95 \%$ C.I. 42 - 62, Relative variate $6.6-$ statistically significant).

Table 2. Cervical length and mode of delivery and mode of onset of labour.

\begin{tabular}{|c|c|c|c|c|c|c|}
\hline \multirow{2}{*}{ Mode of Delivery } & \multirow{2}{*}{ Onset of Labor } & \multicolumn{4}{|c|}{ Cervical Length } & \multirow{2}{*}{$p$ value } \\
\hline & & $<2 \mathrm{~cm}$ & $2-2.9 \mathrm{~cm}$ & $3-3.9 \mathrm{~cm}$ & $\geq 4 \mathrm{~cm}$ & \\
\hline \multirow{3}{*}{ NVD } & Spontaneous & 2 & 16 & 16 & 5 & \multirow{9}{*}{$\begin{aligned}{ }^{*} \mathrm{p} & >0.10 \\
{ }^{* *} \mathrm{p} & <0.001\end{aligned}$} \\
\hline & Induced & 0 & 0 & 14 & 2 & \\
\hline & Total & 2 & 16 & 30 & 7 & \\
\hline \multirow{3}{*}{ Instrumental } & Spontaneous & 0 & 0 & 0 & 0 & \\
\hline & Induced & 0 & 0 & 2 & 1 & \\
\hline & Total & $\mathbf{0}$ & $\mathbf{0}$ & 2 & 1 & \\
\hline \multirow{3}{*}{ LSCS } & Spontaneous & 1 & 1 & 4 & 1 & \\
\hline & Induced & 0 & 2 & 10 & 23 & \\
\hline & Total & 1 & $3^{*}$ & $14^{* / * *}$ & $24^{* *}$ & \\
\hline
\end{tabular}

*Shows the p value when the group with a cervical length of $2-2.9 \mathrm{~cm}$ was compared to the group with cervical length of 3 - $3.9 \mathrm{~cm}$; ${ }^{* *}$ Shows the $\mathrm{p}$ value when the group with a cervical length of $3-3.9 \mathrm{~cm}$ was compared to the group with cervical length of $\geq 4 \mathrm{~cm}$.

Table 3. Cervical length and indications for LSCS.

\begin{tabular}{|c|c|c|c|c|c|}
\hline \multirow{2}{*}{ Indications } & \multicolumn{5}{|c|}{ Cervical length ( cm) } \\
\hline & $<2$ & $2-2.9$ & $3-3.9$ & $\geq 4 \mathrm{~cm}$ & Total \\
\hline Failure to progress & 0 & $1(6 \%)$ & $4(25 \%)$ & $11(69 \%)$ & $16(100 \%)$ \\
\hline Failed Induction & 0 & $1(8 \%)$ & $2(17 \%)$ & $9(75 \%)$ & $12(100 \%)$ \\
\hline Fetal distress & $1(8 \%)$ & $1(8 \%)$ & $7(58 \%)$ & $3(25 \%)$ & $12(100 \%)$ \\
\hline Deep transverse arrest/CPD & 0 & 0 & $1(50 \%)$ & $1(50 \%)$ & $2(100 \%)$ \\
\hline Total & $1(2.3 \%)$ & $3(7.1 \%)$ & $14(33.3 \%)$ & $26(61.9 \%)$ & $42(100 \%)$ \\
\hline
\end{tabular}


The receiving operator characteristic curves using SPSS 17.00 software were calculated to illustrate true positive results (sensitivity) versus false positive results (1-specificity), as the cutoff for the test was shifted from low (0.1) to high (0.914). The diagnostic accuracy as given by the area under ROC curve is 0.774 (95\% CI 0.677 0.877). ROC curve analysis of cervical length found a cutoff value that, in some way, minimized the number of false positives and false negatives. Test cut off value for our ROC graph was 4 , which means a mid pregnancy cervical length of $4 \mathrm{~cm}$ has the highest specificity and sensitivity in predicting the rates of cesarean section (Figure 1). Sensitivity, specificity, positive predictive value, negative predictive value of cervical length was $54.8 \%, 91.4 \%, 82.1 \%$ and $73.6 \%$ respectively.

Multiple logistic regression analysis was performed to analyze the relationship between mode of delivery and various clinical and ultrasonographic variables. The variables analyzed included maternal age, cervical length, gestational age at transvaginal sonography, gestational age at onset of labour/induction of labour, induction of labour and induction to delivery interval. Of these independent variables, cervical length by transvaginal sonography and induction to delivery interval were found to be significantly affecting the mode of delivery $(\mathrm{p}<0.05$ (Table 5).

\section{$\mathbf{R}^{2}$ (Coefficient of Determination)}

$\mathrm{R}^{2}$ (coefficient of determination) was calculated to calculate the percentage increase in risk of caesarean section with increase in cervical length.

$$
\mathrm{R}^{2}=0.271
$$

This means that there is a $27.1 \%$ increase in risk of cesarean section with every $1 \mathrm{~cm}$ increase in cervical length. Odds ratio for cesarean section was $1.229(95 \% \mathrm{CI}=0.825$ - 1.633; $\mathrm{p} \leq 0.001)$.

ROC Curve

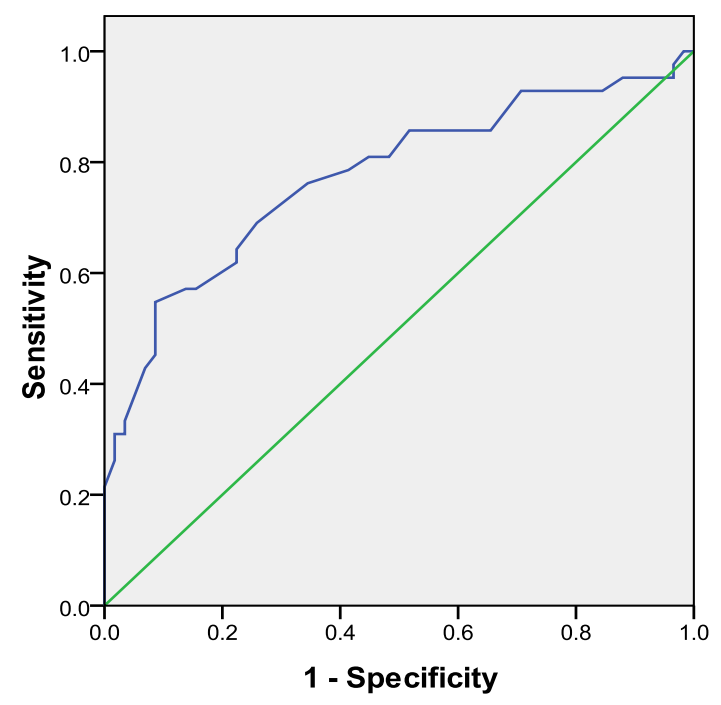

Diagonal segments are produced by ties.

Figure 1. ROC curve analysis of cervical length found a cutoff value that, in some ways, minimizes the number of false positives and false negatives. Minimizing the false positives and false negatives is the same as maximizing the sensitivity and specificity. Thus, a good first choice for a test cutoff value is that value which corresponds to a point on the ROC curve nearest to the upper left corner of the ROC graph which is $4.0 \mathrm{~cm}$. This means $4 \mathrm{~cm}$ is the discriminatory value beyond which risk of caesarean section increases significantly. The diagnostic accuracy as given by the area under ROC curve is 0.774 (95\% CI 0.677 - 0.877 ). The sensitivity, specificity, positive predictive value, negative predictive value for cervical length for prediction of caesarean section was $54.8 \%$, $91.4 \%, 82.1 \%$, $73.6 \%$ respectively. 
Table 4. Cervical length and induction to delivery duration.

\begin{tabular}{|c|c|c|c|c|c|c|}
\hline \multirow{2}{*}{\multicolumn{2}{|c|}{ Induction to delivery duration }} & \multicolumn{4}{|c|}{ Cervical Length } & \\
\hline & & $<2 \mathrm{~cm}$ & $2-2.9 \mathrm{~cm}$ & $3-3.9 \mathrm{~cm}$ & $\geq 4 \mathrm{~cm}$ & \\
\hline \multirow{2}{*}{$<6 \mathrm{hrs}$} & $\mathrm{n}$ & 2 & 4 & 5 & 0 & \\
\hline & $\%$ & $66.7 \%$ & $21.1 \%$ & $10.9 \%$ & $0.0 \%$ & \\
\hline \multirow{2}{*}{$6-12 \mathrm{hrs}$} & $\mathrm{n}$ & 1 & 13 & 28 & 9 & \\
\hline & $\%$ & $33.3 \%$ & $68.4 \%$ & $60.9 \%$ & $28.1 \%$ & \\
\hline \multirow{2}{*}{$13-24$ hrs } & $\mathrm{n}$ & 0 & 1 & 4 & 8 & $\mathrm{p}<0.001$ \\
\hline & $\%$ & $0.0 \%$ & $5.3 \%$ & $8.7 \%$ & $25.0 \%$ & \\
\hline \multirow{2}{*}{$>24 \mathrm{hrs}$} & $\mathrm{n}$ & 0 & 1 & 9 & 15 & \\
\hline & $\%$ & $0.0 \%$ & $5.3 \%$ & $19.6 \%$ & $46.9 \%$ & \\
\hline \multicolumn{2}{|c|}{ Total } & 3 & 19 & 46 & 32 & \\
\hline
\end{tabular}

${ }^{*} \mathrm{n}=$ Number of women.

Table 5. Multiple logistic regression analysis to predict mode of delivery. The outcome variable studied was mode of delivery (vaginal/LSCS).

\begin{tabular}{cccc}
\hline & P value & Odds Ratio & 95.0\% C.I. \\
Maternal age & 0.893 & 0.990 & 0.850 \\
Cervical length & 0.026 & 2.273 & 1.102 \\
GA at TVS & 0.239 & 1.292 & 0.843 \\
GA at onset/inductin of labour & 0.796 & 0.958 & 0.690 \\
Mode of induction (induced) & 0.175 & 2.633 & 0.650 \\
Induction to delivery interval & 0.031 & 1.051 & 1.980 \\
\hline
\end{tabular}

*GA-Gestational age.

\section{Discussion}

A number of studies have been conducted to find the association between increased risk of primary cesarean section in patients with long cervical length [1] [4].

C A Kalu et al. [4] studied the role of mid pregnancy transvaginal cervical length measurement in prediction of pregnancy outcome and concluded that long mid trimester transvaginal cervical length could predict risk of cesarean section. His study showed that the cervical length at a mean gestational age of 22 weeks was positively associated with increasing gestational age at delivery ( $p$ value $<0.001$ ) and the risk for cesarean section increased progressively with the increase in cervical length at mid-pregnancy. The rate of cesarean section seemed to increase significantly at cervical lengths of above $40 \mathrm{~mm}$ and indeed doubled when compared with the rate of cesarean section below $40 \mathrm{~mm}$ in his study. The risk of cesarean section for poor progress was significantly associated with an increasing cervical length of more than $40 \mathrm{~mm}$. The association between the quartiles of cervical length and the cesarean section for other indications was not significant (p value 0.073). He also showed that the odds for cesarean section due to poor progress in labor at term had negative correlation with cervical length quartiles of $40 \mathrm{~mm}$ and below (p value $>0.05$ ), while the odds ratio for cesarean section due to poor progress in labor was positively related $(\mathrm{OR}=3.37, \mathrm{RR}=3.40,95 \%$ confidence interval $1.60-7.00$, $\mathrm{p}$ value $=$ 0.0008 ) for cervical length of $40 \mathrm{~mm}$ and above.

G C Smith et al. [1] found that women with cervical lengths of $40-67 \mathrm{~mm}$ at mid pregnancy were 1.81 times more likely than women with cervical lengths of 16 - $30 \mathrm{~mm}$ to need cesarean deliveries. Women with a midpregnancy cervical length in the lowest quartile $(16-30 \mathrm{~mm})$ had the lowest rate of cesarean delivery, at 16.0 percent. This was significantly lower than the rates of 18.4 percent for those in the second quartile (31 - $35 \mathrm{~mm})$, 21.7 percent for those in the third quartile ( 36 - $39 \mathrm{~mm}$ ), and 25.7 percent for those in the fourth quartile (40 - 67 
$\mathrm{mm}$ ). A total of 5542 women underwent cesarean delivery in the study by Smith et al.; in 4615 (83.3\%) of these procedures, failure to progress in labor was included in the list of indications. The rate of cesarean delivery started to increase at a cervical length of $25 \mathrm{~mm}$ and plateaued at a cervical length of $50 \mathrm{~mm}$, doubling across the range of observed values. They concluded that the risk for cesarean delivery was attributable to cervical length in midpregnancy and that a long cervix in midpregnancy was associated with failure to progress during labor.

In our study, amongst the 58 normal vaginal births, only $9.1 \%$ were beyond 40 weeks whereas amongst the total of 42 cesarean deliveries only $7.1 \%$ were before 37 weeks ( $\mathrm{p} \leq 0.001)$.

We have observed that, $57 \%$ of pregnancies had onset of labour/induction at gestation age of 37 - 40 weeks and $19 \%$ had at $>40$ weeks and only $24 \%$ at $<37$ weeks. Mean gestation age was $38.24 \pm 2.67$ weeks. Similar results were shown by Kalu et al. [4], who observed a mean gestational age at birth to be 37 - 39 weeks. Joydev et al. [9] studied cervical length distribution in pregnant females in Eastern India and their gestational age at delivery and mode of delivery and observed a mean gestational age of 38.1 weeks at delivery.

All women, in the study population, with cervical length $<2 \mathrm{~cm}$ had preterm delivery ( $<37$ weeks).Thirty one out of $46(67.4 \%)$ women with cervical length $3-3.9 \mathrm{~cm}$ had onset of labor between 37 - 40 week and 73.7\% with cervical length between $2-2.9 \mathrm{~cm}$ had onset of labor at $<37$ week $(\mathrm{p}<0.001)$. In the group of women had a cervical length of $\geq 4 \mathrm{~cm}, 26$ women, out of a total of 32, had induced labor beyond 40 weeks of gestation. G C Smith et al. [1] and C Kalu et al. [4] also showed increase in gestation age at onset of labor/induction with increase in cervical length. In the study by G C Smith et al. [1], gestational age at onset of labor increased from 40 weeks in $<40 \mathrm{~mm}$ to 40.3 week in $>40 \mathrm{~mm}$. Similarly, Kalu et al. [4] studied that mean gestation age at onset of labor was 36.1 weeks in group with cervical length 15 - $19 \mathrm{~mm}$ and 39.24 weeks in group with cervical length $\geq 4 \mathrm{~cm}$.

Correlation between gestational age at onset of labor, mode of onset of labor and cervical length showed that, in our study, statistically significant higher rates of induction of labor were observed with increase in cervical lengths in the groups studied ( $\mathrm{p} \leq 0.001$ for those with cervical lengths between $2-2.9$ versus those with $3-3.9$ $\mathrm{cm}$ cervical lengths; $\mathrm{p}=0.02$ for groups with cervical lengths $3-3.9$ versus $\geq 4 \mathrm{~cm}$ ). This showed a positive correlation with gestation age and need for induction and cervical length. Intragroup comparisons, however, showed that the difference in the rates spontaneous onset of labor and induced labor was not statistically significant in those women with cervical lengths between 3 - $3.9 \mathrm{~cm}$ (S.E.(P) = 5; 95\% CI 42 - 62, Relative variate 1.6) but the induced labor rate was significantly higher in women with cervical lengths $\geq 4 \mathrm{~cm}$ (S.E.(P) $=5$; $95 \% \mathrm{CI}$ 42 - 62, Relative variate 6.6).

In our study, out of 32 women with cervical length $\geq 4 \mathrm{~cm}$, 24 women (75\%) had LSCS ( $<<0.0001$ ). Of the total 42 cesareans done in our study, 24 (57.1\%), had a cervical length $\geq 4 \mathrm{~cm}(\mathrm{p} \leq 0.0001)$. Intergroup comparisons showed that the difference in the cesarean rates between those with cervical lengths $<3 \mathrm{~cm}$ and those with cervical lengths between $3-3.9 \mathrm{~cm}$ was not statistically significant $(\mathrm{p}=0.10)$. However, when the group with cervical length between $3-3.9 \mathrm{~cm}$ was compared to the group with cervical length $\geq 4 \mathrm{~cm}$, the difference in the cesarean rates was statistically significant $(\mathrm{p} \leq 0.001)$. Similar results were seen in study by C A Kalu et al. [4] who showed that $50 \%$ women with cervical length $\geq 4 \mathrm{~cm}$ had cesarean section. This was also supported by G C Smith et al. [1], who also found an increase in risk of cesarean section with increasing cervical length. Thus, in our study, it was observed that there was increase need for induction in patients with cervical length $>3 \mathrm{~cm}$ and there were increased chances of need for LSCS in patients with cervical length $\geq 4 \mathrm{~cm}$.

Studies conducted by KH Park et al. [10] and HM Tanir [11] showed a mean cervical length in the women of successful and failed induction of $25.5 \pm 6.4 \mathrm{~mm}$ and $30.2 \pm 7.3 \mathrm{~mm}$; and $26.0 \pm 7.2 \mathrm{~mm}$ and $34.3 \pm 7.4 \mathrm{~mm}$ respectively. In both the studies the difference in between the mean cervical length was found to be statistically significant. However, studies by Paterson et al. [3], Gonen R et al. [12], and Watson WJ et al. [13] failed to show any significant role of cervical length by TVS in prediction of successful induction. The mean cervical length for spontaneous labor in our study was significantly lower than the mean for induced labor (3.11 \pm 0.85 versus $4.36 \pm 1.11 \mathrm{~cm} ; \mathrm{p} \leq 0.001)$.

Statistically significant higher number of cesarean section in patients with cervical length $\geq 4 \mathrm{~cm}$ were due to failure to progress and failed induction ( 28 of $42,66.7 \%$, S.E.(P) $=5$; 95\% CI 42 - 62, Relative variate 2.8). C A Kalu et al. [4] observed in their study that around $54 \%$ of cesarean section were due poor progress of labor in patients with cervical length $\geq 4 \mathrm{~cm}$. G C Smith et al. [1] observed 30\% cesarean due to failure to progress in the same group. 
The sensitivity, specificity, positive predictive value, negative predictive value of cervical length for cesarean section at $\geq 4 \mathrm{~cm}$ was $54.8 \%$, 91.4\%, 82.1\% and 73.6\% respectively. Gomez et al. [14] studied sensitivity, specificity, positive predictive value and negative predictive value of cervical length in preterm labor , which was 73\%, 78\%, 68\% and 83\% respectively for cervical length of $<18 \mathrm{~mm}$. Centin M et al. [2] studied the same for cervical length of $30 \mathrm{~mm}$ and it was $100 \%$, 45.9\%, 58.3\% and 100\% respectively.

Table 4 shows that $46.9 \%$ with cervical length $\geq 4 \mathrm{~cm}$ had induction to delivery interval of $>24$ hours and $66.7 \%$ with cervical length $<2 \mathrm{~cm}$ delivered in $<6$ hours $(\mathrm{p}<0.001)$. Thus, there was a significant increase in induction to delivery interval with increase in cervical length in our study. Rane et al. [15] studied the role of ultrasonography in prediction of successful induction of labor. They concluded that prediction of induction to delivery interval was influenced by preinduction cervical length.

Our study showed that mid trimester transvaginal ultrasonographic measurement of cervical length was a good predictor of mode of delivery. Cervical length of $\geq 4 \mathrm{~cm}$ was associated with increased risk of primary cesarean section, increased need for induction and increase induction to delivery interval. In the receiver operating characteristic (ROC) curve analysis, the best cut-off point for prediction of primary cesarean section was 40 mm for cervical length, Sensitivity, specificity, positive predictive value, negative predictive value of Cervical Length was $54.8 \%, 91.4 \%, 82.1 \%$ and $73.6 \%$ respectively.

$\mathrm{R}^{2}$ (coefficient of determination) was ,calculated in our study, to estimate the percentage increase in risk of caesarean section with increase in cervical length which showed that there is a $27.1 \%$ increase in risk of cesarean section with every $1 \mathrm{~cm}$ increase in cervical length. Odds ratio for cesarean section was 1.229 (95\% CI = 0.825 - 1.633; $\mathrm{p} \leq 0.001$ ) in our study.

\section{Conclusion}

Thus, transvaginal cervical length measurement at mid trimester can be used as a predictive tool to determine the possible outcome of labor and risk of cesarean section. However, the numbers of women studied were 100. To formulate a definitive protocol, the study should continue with a large number of women.

\section{Limitations of the Study}

A small sample size is the main limitation of our study.

\section{References}

[1] Smith, G.C.S., Celik, E., To, M. and Khouri, O. (2008) Cervical Length at Mid-Pregnancy and Risk of Primary Cesarean Delivery. The New England Journal of Medicine, 358, 1346-1353. http://dx.doi.org/10.1056/NEJMoa0706834

[2] Cetin, M. and Cetin, A. (1997) The Role of Transvaginal Sonography in Predicting Recurrent Preterm Labour in Patients with Intact Membranes. European Journal of Obstetrics and Gynaecology and Reproductive Biology, 74, 7-11. http://dx.doi.org/10.1016/s0301-2115(97)02756-5

[3] Paterson-Brown, S., Fisk, N.M., Edmonds, D.K. and Rodeck, C.H. (1991) Preinduction Cervical Assessment by Bishop's Score and Transvaginal Ultrasound. European Journal of Obstetrics \& Gynecology and Reproductive Biology, 40, 17-23. http://dx.doi.org/10.1016/0028-2243(91)90039-N

[4] Kalu, C.A., Umeora, O.U., Egwuatu, E.V. and Okwor, A.( 2012) Predicting Mode of Delivery Using Mid-Pregnancy Ultrasonographic Measurement of Cervical Length. Nigerian Journal of Clinical Practice, 15, 338-343.

[5] Ware, V. and Raynor, B.D. (2000) Transvaginal Ultrasonographic Cervical Measurement as a Predictor of Successful Labour Induction. American Journal of Obstetrics \& Gynecology, 182, 1030-1032. http://dx.doi.org/10.1067/mob.2000.105399

[6] Yang, S.H., Roh, C.R. and Kim, J.-H. (2004) Transvaginal Ultrasonography for Cervical Assessment before Induction of Labour. Journal of Ultrasound in Medicine, 23, 375-382.

[7] Rane, S.M., Guirgis, R.R., Higgins, B. and Nicolaides, K.H. (2004) The Value of Ultrasound in the Prediction of Successful Induction of Labour. Ultrasound in Obstetrics \& Gynecology, 24, 538-549. http://dx.doi.org/10.1002/uog.1100

[8] Paterson-Brown, S., Fisk, N.M., Edmonds, D.K. and Rodeck, C.H. (1991) Preinduction Cervical Assessment by Bishop's Score and Transvaginal Ultrasound. European Journal of Obstetrics \& Gynecology and Reproductive Biology, 40, 17-23. http://dx.doi.org/10.1016/0028-2243(91)90039-N

[9] Mukherji, J., Anant, M., Ghosh, S., Bhattacharyya, S.K., Hazra, A. and Kamilya, G.S. (2011) Normative Data of Cervical Length in Singleton Pregnancy in Women Attending a Tertiary Care Hospital in Eastern India. Indian Journal of 
Medical Research, 133, 492-496.

[10] Park, K.H. (2007) Transvaginal Ultrasonographic Cervical Measurement in Predicting Failed Labour Induction and Caesarean Delivery for Failure to Progress in Nulliparous Women. Journal of Korean Medical Science, 22, 722-727. http://dx.doi.org/10.3346/jkms.2007.22.4.722

[11] Tanir, H.M., Sener, T. and Yildiz, Z. (2008) Digital and Transvaginal Ultrasound Cervical Assessment for Prediction of Successful Labor Induction. International Journal of Gynecology and Obstetrics, 100, 52-55. http://dx.doi.org/10.1016/j.ijgo.2007.07.014

[12] Gonen, R., Degani, S. and Ron, A. (1998) Prediction of Successful Induction of Labour: Comparison of Transvaginal Ultrasonography and the Bishop Score. European Journal of Ultrasound, 7, 183-187. http://dx.doi.org/10.1016/S0929-8266(98)00042-1

[13] Watson, W.J., Stevens, D., Welter, S. and Day, D. (1996) Factors Predicting Successful Labour Induction. Obstetrics \& Gynecology, 88, 990-992. http://dx.doi.org/10.1016/S0029-7844(96)00321-3

[14] Gomez, R., Galasso, M., Romero, R., Mazor, M., Sorokin, Y., Goncalves, L. and Treadwell, M. (1994) Ultrasonographic Examination of the Uterine Cervix Is Better than Cervical Digital Examination as a Predictor of the Likelihood of Premature Delivery in Patients with Preterm Labor and Intact Membranes. American Journal of Obstetrics \& Gynecology, 171, 956-964. http://dx.doi.org/10.1016/0002-9378(94)90014-0

[15] Rane, S.M., Guirgis, R.R, Higgins, B. and Nicolaides, K.H. (2004) The Value of Ultrasound in the Prediction of Successful Induction of Labor. Ultrasound in Obstetrics \& Gynecology, 24, 538-549. http://dx.doi.org/10.1002/uog.1100 